\title{
Genome-wide expression links the electron transfer pathway of Shewanella oneidensis to chemotaxis
}

\author{
Shang-Kai Tai', Guanl Wu'1, Shinsheng Yuan¹ and Ker-Chau Li*1,2
}

\begin{abstract}
Background: By coupling the oxidation of organic substrates to a broad range of terminal electron acceptors (such as nitrate, metals and radionuclides), Shewanella oneidensis MR-1 has the ability to produce current in microbial fuel cells (MFCs). omcA, mtrA, omcB (also known as $m t r C$ ), $m t r B$, and gspF are some known genes of $S$. oneidensis MR- 1 that participate in the process of electron transfer. How does the cell coordinate the expression of these genes? To shed light on this problem, we obtain the gene expression datasets of MR-1 that are recently public-accessible in Gene Expression Omnibus. We utilize the novel statistical method, liquid association (LA), to investigate the complex pattern of gene regulation.
\end{abstract}

Results: Through a web of information obtained by our data analysis, a network of transcriptional regulatory relationship between chemotaxis and electron transfer pathways is revealed, highlighting the important roles of the chemotaxis gene cheA-1, the magnesium transporter gene mgtE-1, and a triheme c-type cytochrome gene SO4572.

Conclusion: We found previously unknown relationship between chemotaxis and electron transfer using LA system. The study has the potential of helping researchers to overcome the intrinsic metabolic limitation of the microorganisms for improving power density output of an MFC.

\section{Background}

Shewanella oneidensis MR-1 (= ATCC $700550=$ CIP 106686 = BCRC 17276), previously designated Alteromonas putrefaciens MR-1 or Shewanella putrefaciens strain MR-1, is a facultative anaerobic gram-negative bacterium with a single unsheathed polar flagellum [1-4]. The strain MR-1, isolated from Oneida Lake in New York, shows bioremediation potential and metabolically versatile properties. Under aerobic conditions, S. oneidensis utilizes oxygen as the final electron acceptor; nevertheless, S. oneidensis undertakes respiration by reducing alternative terminal electron acceptors such as nitrite, sulfite, fumarate, metals $[\mathrm{Mn}(\mathrm{III} / \mathrm{IV}), \mathrm{Fe}(\mathrm{III})$, and $\mathrm{Cr}(\mathrm{VI})]$, and radionuclides $[\mathrm{U}(\mathrm{VI})$ and $\mathrm{Pu}(\mathrm{IV})]$ under anaerobic environment [5-10]. The remarkable anaerobic respiratory plasticity (ARP) involves many genes. In this study, we only considered a subset, $c y m A, m \operatorname{tr} A, m \operatorname{tr} B, o m c B$ (also known as $m t r C)$, omc $A, g s p F$, and $g s p D$ genes [11,12].

\footnotetext{
* Correspondence: kcli@stat.sinica.edu.tw

1 Institute of Statistical Science, Academia Sinica, Taipei 115, Taiwan Full list of author information is available at the end of the article
}

The functions of these ARP genes have been characterized. The gene cymA (locus tag SO4591) encodes a cytoplasmic membrane-bound, tetraheme cytochrome $c$ that serves as an entry point for electron flow from the cytoplasm to decaheme cytochrome $c$, encoded by $m$ tr $A$ (SO1777) [11-13]. The electrons are relayed through the periplasm to the outer membrane $(\mathrm{OM})$ protein encoded by the gene $m t r B$ (SO1776) [11-13], which also plays a role required for the proper localization and insertion of cytochromes OmcB (SO1778) and OmcA (SO1779) into the OM $[11,13,14]$. OmcB interacts directly with OmcA to form a stable complex as part of the electron transport pathway $[11,13,15]$. OmcA is a cell surface-exposed lipoprotein, that has been shown to be involved in the process of electron transfer to electrodes in microbial fuel cells (MFCs) $[11,13,16,17]$. On the cell surface, exposure of the OmcA allows it to directly contact with extracellular electron acceptors [16]. Both genes $g s p F$ (SO0168) and $g s p D$ (SO0166) encode individual components of the type II secretion system (T2S). Pseudopilus apparatus of T2S, whose formation can be regulated by GspF, delivers 
OmcB and OmcA from periplasm across GspD into the surroundings where the OmcB-OmcA complex is constructed $[12,18]$.

We are interested in studying how the cell coordinate the expression of these seven ARP genes. There are a total of 4,931 predicted protein-encoding open reading frames (CDSs) in S. oneidensis MR-1, comprising a circular chromosome and an iteron-type plasmid with 4,758 and 173 CDSs respectively [7]. Genome-wide gene expression profiling has been a powerful method in elucidating the gene regulation patterns in cells $[19,20]$. For example, the well-known yeast gene expression dataset [21], originally collected for finding cell cycle-regulated genes, has been used by some authors to study biological mechanisms beyond the cell-cycle events [22-24]. Inspired by such successes, we searched NCBI Gene Expression Omnibus [25] for experiments performed on the strain MR-1 and found three such datasets, series GSE3876, GSE4489, and GSE7973. They were generated by the spotted cDNA microarray method. We combined these three gene expression datasets to form a full dataset (denoted by gpl3253_cia) with 88 conditions for investigation. Our aim is to study how the expression of the aforementioned genes of electron transfer are coregulated and how they may interact with other genes. We employed the new bioinformatic tool, liquid association (LA), to conduct the data analysis [22,26-28].

LA can be viewed as an extension of the traditional correlation measure which is commonly employed in gene expression studies for identifying gene clusters. Genes with similar expression profiles, as reflected by significant correlation coefficient, tend to form common structure components, to be regulated by common transcription elements, and to participate in the same biological pathways. However, many functionally associated genes are uncorrelated in expression [29]. LA is a method for identifying higher order association between variables in complex systems. It is particularly useful when the correlation between two variables $\mathrm{X}, \mathrm{Y}$ is weakened due to the mediation by a third variable $Z$. LA depicts how the pattern of correlation between $X$ and $Y$, including its sign and strength, is mediated by $\mathrm{Z}$.

We uploaded gpl3253_cia to the LA online computing system. We used each pair of the ARP genes as the lead, $X$ and $\mathrm{Y}$, to generate a short list of genes $\mathrm{Z}$ with the highest LA scores. Through the genes which mediate the correlation patterns of ARP genes, we hope to unravel some biological pathways important to electron transfer process. After examining the LA output, one gene cheA-1 stood out from a pool of near 5000 genes in the genome as the best LA score gene. Examination of the genome of MR-1 showed that this bacterium has two uninterrupted chemotaxis (che) genes, designated cheA-1 (SO2121) and cheA-3 (SO3207) [7,30,31]. CheA (a histidine protein kinase), together with $\mathrm{CheW}$ and $\mathrm{CheZ}$ can control the level of phosphorylation of CheY, which regulates flagellar motion [32]. On the other hand, at least five studies had shown that MR-1 responds chemotactically to a wide range of anaerobic electron acceptors [31,33-36]. In particular, Baraquet et al. showed that the anaerobic respiratory systems are necessary for chemotaxis towards anaerobic electron acceptors [36]. In addition, cheA-3 gene was demonstrated to be essential for the chemotactic behavior in MR-1 [31]. Putting together, our results suggest a mediating role for cheA-1 in the chemotactic responses to anaerobic electron acceptors. Encouraged by this finding, we further conducted a series of LA analysis and reported additional results for cheA and other genes.

\section{Results}

We have conducted a series of LA analysis as depicted in Figure 1. Our findings can be summarized by Figure 2, which shows three most significant LA-scouting genes cheA-1, mgtE-1 and SO4572, that affect many pairs of the anaerobic respiration genes. The chemotaxis gene cheA-1 is already discussed earlier. The second gene $m g t E-1$ found in our LA analysis encodes a magnesium transporter, suggesting a possible connection between electron transfer and the magnesium transport system in $S$. oneidensis. This is consistent with a recent study on cobalt reduction wherein the authors found not only the critical involvement of the Mtr respiratory proteins (including MtrA, MtrB, OmcB) but also pointed out that the process could be influenced by magnesium concentrations [37]. Furthermore, the ability of electricity production and Fe(III) reduction in S. oneidensis is similar to that in the bacterium Aeromonas hydrophila [38], of

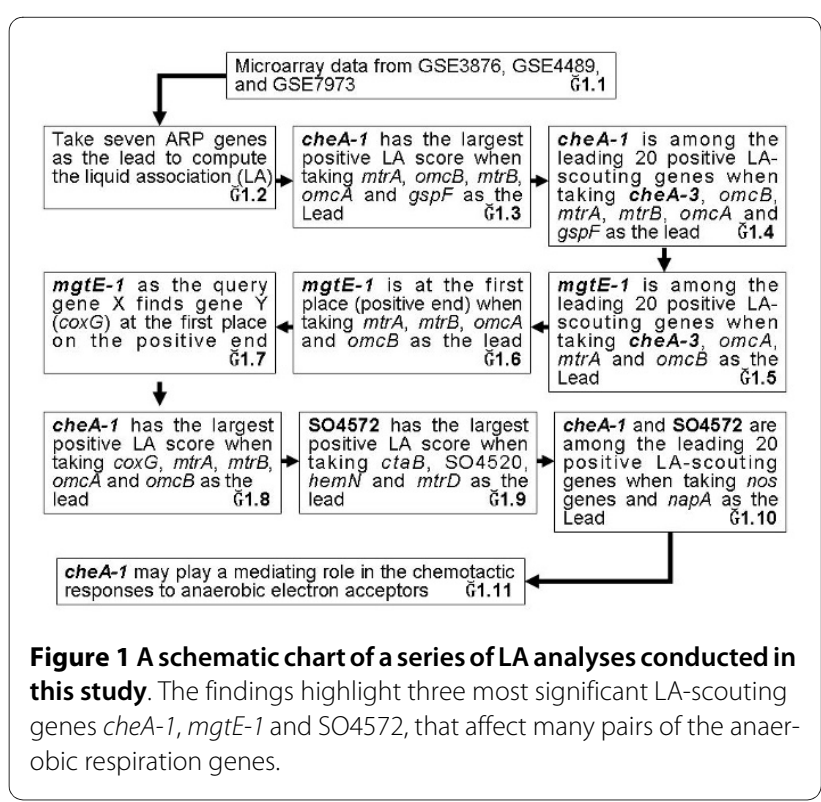




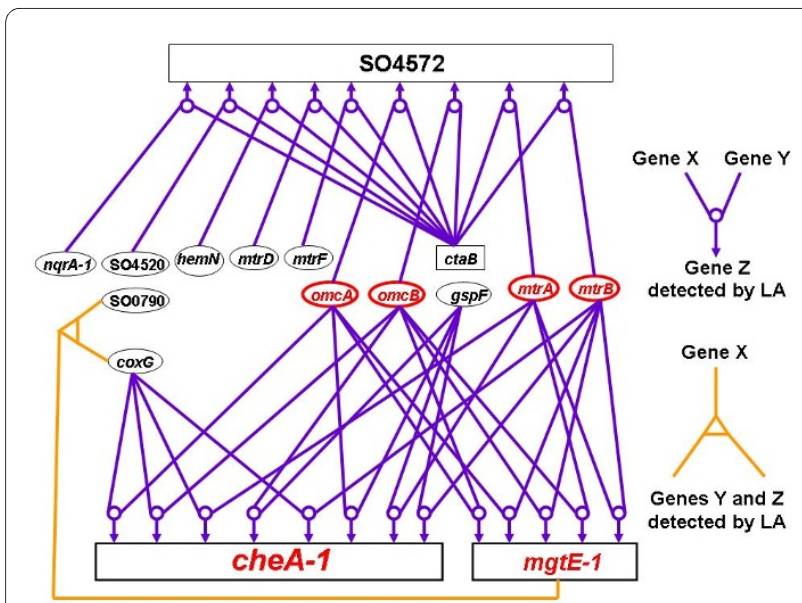

Figure $\mathbf{2}$ Liquid association (LA) network analysis. The LA-scouting genes are occupied at the first place on the positive end of best LA score gene list. The purple arrows point to the mediator genes under the $L A$ score system with $X$ and $Y$ genes as the input. When only one gene $X=m g t E-1$ is given as the input gene, we can find that the gene pair $Y=\operatorname{coxG}, Z=$ SO0790 appears at the first place on the positive score end (the orange line).

which some $m g t E$ mutants showed significantly reduced swarming in semisolid swarming agar [39]. Chemotaxis is essential for swarming motility in bacteria [40]. Thus our finding brings out a likely coordinative gene regulation between the chemotaxis pathway, the electron transfer and the magnesium transport system. SO4572 encodes a triheme $c$-type cytochrome. A deletion mutant of SO4572, along with mutants of $m \operatorname{tr} A, m \operatorname{tr} B$, and $o m c B /$ $o m c A$, was found to be limited in solid Fe oxide (HFOM) reduction relative to the wild type [13]. Interestingly, our LA network also showed that omcA, omcB, mtrA and $m$ tr $B$ genes are connected to cheA-1, $m g t E-1$, and SO4572.

\section{The leading LA-scouting gene cheA-1}

To study the co-expression pattern between seven ARP genes, we took them as genes $\mathrm{X}$ and $\mathrm{Y}$ to explore gpl3253_cia using the LA system as shown in block 1.2 of Figure 1. The outputs of a short list of 20 genes $\mathrm{Z}$ with the best LA scores from the positive and the negative ends are given in Additional file 1. For $\mathrm{X}=o m c A, m \operatorname{tr} A, o m c B$, or $m \operatorname{tr} B, \mathrm{Y}=g s p F$, the gene $\mathrm{Z}$ with the highest score $L A(X, Y \mid Z)$ is cheA-1. In addition, cheA-1 also appears in the outputs of (omcA, gspF), (mtrA, gspF), (omcB, gspF), and $(m t r B, g s p F)$ with significant $P$ values (Table 1$)$. As one anonymous referee pointed out, genes cymA, $m \operatorname{tr} A$, $m \operatorname{tr} B$ and $o m c B$ were controlled by a global transcriptional regulator CRP [41,42]. We conducted LA analysis using $m \operatorname{tr} B$, omcB, $m$ trA and $c r p$ (SO0624) as the lead and found cheA-1 again (Additional file 2).

\section{cheA-3-ARP gene-initiated liquid association search identifies cheA-1}

In the S. oneidensis MR-1, cheA-3 gene was necessary for chemotactic behavior [31]. It would be interesting to know how cheA-3 may be associated with the electron transport, as shown in block 1.4 of Figure 1, we take che $A-3$, omcB, $m \operatorname{tr} A$, omc $A, m \operatorname{tr} B$ and $g s p F$ as the lead to explore gpl3253_cia. Interestingly, we find the gene cheA1 among the leading 20 positive LA-scouting genes (Table 2). Because cheA-3 was essential for chemotactic responses to anaerobic electron acceptors [31], this provided additional evidence about the suggested role of cheA-1 as discussed above.

\section{The leading LA-scouting gene mgtE-1}

Moving to block 1.5 of Figure 1, we find $m g t E-1$ among the leading 20 positive LA-scouting genes when taking cheA-3, omcA, mtrA and omcB as the lead (Table 3). Interestingly, as shown in block 1.6, a positive LA-scouting gene $m g t E-1$ at the first place is found after taking $m \operatorname{tr} A, m \operatorname{tr} B$, omc $A$ and $o m c B$ as $\mathrm{X}$ and $\mathrm{Y}$ (Table 3 ). As one referee pointed out, genes $m \operatorname{tr} B, m \operatorname{tr} A, o m c B$ and $o m c A$ are located in a cluster and may be part of the same operon. On the other hand, $g s p D, g s p E$ (SO0167) and $g s p F$ are in another cluster. Interestingly, $m g t E-1$ resulted from the LA analysis on gene pairs in the first cluster, while cheA-1 resulted from the LA analysis on gene pairs from different clusters.

\section{mgtE-1-initiated genome-wide liquid association search identifies coxG}

We treat $m g t E-1$ as the query gene $\mathrm{X}$ and evaluate the LA score for every pair of genes $(\mathrm{Y}, \mathrm{Z})$ at block 1.7 of Figure 1 . We found both genes $Y=\operatorname{cox} G$ (encoded cytochrome $c$ oxidase) and Z = SO0790 (encoded hypothetical protein) at the first place on the positive end. Moving to block 1.8, we also found $c h e A-1$ with the largest positive LA score after taking $\operatorname{cox} G, m \operatorname{tr} A, m t r B, o m c A$ and $o m c B$ as $\mathrm{X}$ and $\mathrm{Y}$. Within the interior of cell aggregates, aggregate formation may establish the ecological conditions to enhance anaerobic metabolism [43]. Under aerobic-aggregated conditions, $\operatorname{cox} G$, haem $c$ biosynthesis genes (including SO4520, ctaB, hemB-1 and hemN), anaerobic electron transfer genes ( $m$ trF and $m t r D)$ and Na-translocating NADH-quinone reductase genes (nqrA-1 and nqrB-1) were all upregulated [43]. From the analysis performed at block 1.9 of Figure 1, the gene with the largest positive LA score turns out to be SO4572 after taking genes (including $c t a B, \mathrm{SO} 4520$, hem $N$ and $m t r D$ ) involved in anaerobic respiration as $\mathrm{X}, \mathrm{Y}$. Our result provided new insights on the regulation of the genes (including cheA-1, mgtE-1 and SO4572) that may influence the ability to respire anaerobically in aerobic environments. 
Table 1: Liquid association for a positive LA-scouting gene $Z$ (= cheA-1).

\begin{tabular}{|c|c|c|c|c|c|c|c|}
\hline $\mathrm{X}$ & $\bar{Y}$ & $\mathrm{z}$ & LA score & $\begin{array}{l}\text { XY Corr } \\
(\text { High )* }\end{array}$ & $\begin{array}{l}\text { XY Corr } \\
(\text { Low })+\end{array}$ & $\mathrm{P}$ value & Place $\neq$ \\
\hline$m t r A$ & gspF & cheA-1 & 0.3755 & 0.4750 & -0.2788 & 0.0001 & 1 \\
\hline omcB & gspF & cheA-1 & 0.3765 & 0.4418 & -0.2808 & 0.0001 & 1 \\
\hline$m t r B$ & gspF & cheA-1 & 0.3673 & 0.5123 & -0.1856 & 0.0002 & 1 \\
\hline omcA & gspF & cheA-1 & 0.3185 & 0.3933 & -0.3217 & 0.0008 & 1 \\
\hline omcB & gspD & cheA-1 & 0.2617 & 0.5016 & 0.0480 & 0.0048 & 6 \\
\hline$m t r B$ & gspD & cheA-1 & 0.2164 & 0.4909 & 0.2799 & 0.0149 & 8 \\
\hline$m t r A$ & gspD & cheA-1 & 0.2034 & 0.5095 & 0.1325 & 0.0163 & 9 \\
\hline omcB & mtrB & cheA-1 & 0.2622 & 0.9718 & 0.8416 & 0.0060 & 15 \\
\hline omcA & gspD & cheA-1 & 0.1550 & 0.4553 & 0.0851 & 0.0614 & 16 \\
\hline
\end{tabular}

${ }^{*}$ The correlation between $\mathrm{X}$ and $\mathrm{Y}$ in the high cheA- 1 conditions. ${ }^{+}$The correlation between $\mathrm{X}$ and $\mathrm{Y}$ in the low cheA- 1 conditions. ${ }^{*}$ The place on the positive end is held by $Z$.

\section{Nitrous oxide (a potent greenhouse gas) study using liquid association}

Nitrate reductase (NapA) reduces nitrate $\left(\mathrm{NO}_{3}{ }^{-}\right)$to nitrite $\left(\mathrm{NO}_{2}{ }^{-}\right)$. After that, nitrite respiration may proceeds in two different ways [44]. In respiratory denitrification, nitrite is reduced sequentially to nitric oxide (NO), nitrous oxide $\left(\mathrm{N}_{2} \mathrm{O}\right)$, and dinitrogen $\left(\mathrm{N}_{2}\right)$ involving nitrous oxide reductase (Nos). Alternatively, nitrite can also be reduced to ammonium $\left(\mathrm{NH}_{4}^{+}\right)$by the nitrite reductase (NrfA) and Cruz-García et al. showed that anaerobic cultures of MR1 grown with nitrate displayed sequential reduction of nitrate to nitrite and then to ammonium [44]. However, the authors also reported the unexpected detection of nitrous oxide and dinitrogen at the same time. The MR-1 genome includes five nos genes: nos $A$, nos $L$, nos $D$, nos $F$ and $n o s Y$. From the analysis performed at block 1.10 of Figure 1, we can find $c h e A-1$ and SO4572 among the leading 20 positive LA-scouting genes after taking nos $F$, nos $D$ and napA as $\mathrm{X}$ and $\mathrm{Y}$ to explore gpl3253_cia (Table 4). The results suggested that little nitrous oxide and dinitrogen detected in Cruz-García et al.'s experiment might be produced by the complex regulatory mechanism between nos genes, napA, SO4572 and cheA-1. MR-1 chemotaxis to nitrate and nitrite was reported in the literature [33]. This further supports the scenario of napA, cheA-1 and SO4572 involvement in affecting $\mathrm{N}_{2} \mathrm{O}$ emission by $S$. oneidensis MR-1.

As suggested by one referee, we used computer to select one thousand pairs of genes randomly from the pool of anaerobic respiration-irrelevant genes (about 4000 genes) and conduct the LA analysis to find out how likely cheA-1 and SO4572 will appear as the leading mediator gene by chance. It turns out that cheA-1 was detected only 24 times and SO4572 was detected 6 times. Thus statistically, the chance is only $2.4 \%$ and $0.6 \%$ respectively that our findings might be an artifact.

\section{Discussion and Conclusions}

All LA plots are easy to create online using our LA system. Figure 3 shows the coexpression pattern change between $o m c A$ and $g s p F$ as mediated by gene $c h e A-1$. When the expression level of cheA-1 is high (conditions

Table 2: cheA-3-ARP gene-initiated liquid association search identifies cheA-1.

\begin{tabular}{|c|c|c|c|c|c|c|c|c|}
\hline $\mathrm{x}$ & $\mathrm{Y}$ & $\mathrm{Z}$ & LA score & $\begin{array}{l}\text { XY Corr } \\
(\mathrm{High}) *\end{array}$ & $\mathrm{XY}$ & Corr (Low) $\dagger$ & $\mathrm{P}$ value & Place \\
\hline cheA-3 & omcB & cheA-1 & 0.2970 & 0.7545 & & 0.4977 & 0.0018 & 3 \\
\hline cheA-3 & $m t r A$ & cheA-1 & 0.2321 & 0.7804 & & 0.5394 & 0.0070 & 3 \\
\hline cheA-3 & mtrB & cheA-1 & 0.2494 & 0.8241 & & 0.6263 & 0.0077 & 5 \\
\hline cheA-3 & omcA & cheA-1 & 0.1732 & 0.6860 & & 0.4945 & 0.0474 & 5 \\
\hline cheA-3 & gspF & cheA-1 & 0.2435 & 0.9016 & & 0.4166 & 0.0088 & 15 \\
\hline
\end{tabular}

*The correlation between $\mathrm{X}$ and $\mathrm{Y}$ in the high cheA-1 conditions. ${ }^{+}$The correlation between $\mathrm{X}$ and $\mathrm{Y}$ in the low cheA-1 conditions. ${ }^{*}$ The place on the positive end is held by $Z$. 
Table 3: Liquid association for a positive LA-scouting gene $Z$ (= mgtE-1).

\begin{tabular}{|c|c|c|c|c|c|c|c|}
\hline $\mathrm{x}$ & $\mathrm{Y}$ & $\mathrm{z}$ & LA score & $\begin{array}{l}\text { XY Corr } \\
\text { (High)* }\end{array}$ & $\mathrm{XY} \operatorname{Corr}($ Low $) \dagger$ & $\mathrm{P}$ value & Place \\
\hline omcB & mtrA & mgtE-1 & 0.3216 & 0.9927 & 0.9780 & 0.0003 & 1 \\
\hline omcB & mtrB & mgtE-1 & 0.3232 & 0.9723 & 0.8796 & 0.0005 & 1 \\
\hline$m t r A$ & mtrB & mgtE-1 & 0.2793 & 0.9750 & 0.9404 & 0.0014 & 1 \\
\hline omcA & omcB & mgtE-1 & 0.2511 & 0.9780 & 0.9929 & 0.0042 & 1 \\
\hline omcA & $m t r B$ & mgtE-1 & 0.2244 & 0.9465 & 0.8814 & 0.0095 & 1 \\
\hline omcA & cheA-3 & mgtE-1 & 0.1624 & 0.7812 & 0.4578 & 0.0449 & 7 \\
\hline$m t r A$ & cheA-3 & mgtE-1 & 0.2087 & 0.7959 & 0.5375 & 0.0105 & 11 \\
\hline omcB & cheA-3 & mgtE-1 & 0.2480 & 0.8017 & 0.5158 & 0.0043 & 13 \\
\hline
\end{tabular}

*The correlation between $\mathrm{X}$ and $\mathrm{Y}$ in the high $m g t E-1$ conditions. ${ }^{\text {TT }}$ The correlation between $\mathrm{X}$ and $\mathrm{Y}$ in the low $m g t E-1$ conditions. ${ }^{\text {*T The place on }}$ the positive end is held by $Z$.

represented by red triangles), a strong positive correlation is seen between $o m c A$ and $g s p F(\mathrm{r}=0.842)$. When cheA-1 is low (blue dots), the association is much decreased $(\mathrm{r}=0.1382)$. A similar interpretation can be given to the LA activity for ( $m \operatorname{tr} B, g s p F),(m \operatorname{tr} A, g s p F)$, and $(o m c B, g s p F)$ with $c h e A-1$ being the positive scouting gene (Figure 4, 5 and 6).

We examined the experimental conditions associated with the differential coexpression pattern found by LA more closely. In Figure 3, the low expression of cheA-1 (blue dots) occurred on the conditions when MR-1 was incubated after a temperature downshift from $30^{\circ} \mathrm{C}$ to $8^{\circ} \mathrm{C}$ over a period of $40-80 \mathrm{~min}$ and the conditions at $30^{\circ} \mathrm{C}$ over a period of $60 \mathrm{~min}$ after the ionizing radiation (IR) exposure (40 Gy). In contrast, the high expression of che $A-1$ (red triangles) tended to occur earlier in response to environmental stress: over a period of 5-20 min after the downshift of temperature, and over a period of 20 min after IR exposure. Putting together, our result showed that the up-regulation of the positive LA-scouting gene che $A-1$ enhanced the co-expression strength of $o m c A, m \operatorname{tr} A, o m c B, m \operatorname{tr} B$ and $g s p F$, thereby increasing the entire electron-flow efficiency. This early response of gene regulation may be an important factor for the survival of MR-1 under environmental stress.
Furthermore, in S. oneidensis MR-1, cheA-3 gene was essential for chemotactic responses to anaerobic electron acceptors [31]. The LA search initiated by pairing cheA-3 with ARP genes identifies cheA-1 (Table 2). In addition, Baraquet et al. showed that at least one major (SO2240) and four minor (SO3282, SO3642, SO3890 and SO4454) methyl-accepting chemotaxis proteins are involved in energy taxis. We also found cheA-1 among the leading 20 positive LA-scouting genes when taking ARP genes and SO2240, SO3282, and SO4454 as the lead (Additional file 3). Our bioinformatic results suggest that che and several ARP genes (also including petC and SO1415, see Additional file 4) are important for the proper functioning of the mechanisms underlying electron acceptor chemotaxis. Based on the assistance of LA analysis, investigators may design experiments to demonstrate that cheA-1 may play a role in optimizing chemotactic behavior. For instance, researchers might study the cheA-1 mutant of MR-1 under IR exposure (40 Gy) and/or cold shock (a temperature downshift from $30^{\circ} \mathrm{C}$ to 8 or $15^{\circ} \mathrm{C}$ ) because our microarray data were extracted from two series GSE3876 (under IR exposure) and GSE4489 (under cold shock).

The slow biotransformation rate of substrates to electrons has been a bottleneck in MFC performance [45].

Table 4: nos gene-napA-initiated liquid association search identifies cheA-1 and SO4572.

\begin{tabular}{|c|c|c|c|c|c|c|c|}
\hline $\mathrm{X}$ & $\mathrm{Y}$ & $\mathrm{Z}$ & LA score & $\begin{array}{l}\text { XY Corr } \\
(\mathrm{High}) \text { * }\end{array}$ & $\mathrm{XY} \operatorname{Corr}($ Low $) \dagger$ & $\mathrm{P}$ value & Place \\
\hline nosf & napA & cheA-1 & 0.3684 & 0.7970 & -0.4956 & 0.00002 & 5 \\
\hline nosD & napA & cheA-1 & 0.2059 & 0.8548 & 0.6178 & 0.01347 & 12 \\
\hline nosf & napA & so4572 & 0.3404 & 0.6923 & 0.2732 & 0.00008 & 17 \\
\hline
\end{tabular}

*The correlation between $\mathrm{X}$ and $\mathrm{Y}$ in the high $\mathrm{Z}$ conditions. ${ }^{\top}$ The correlation between $\mathrm{X}$ and $\mathrm{Y}$ in the low $\mathrm{Z}$ conditions. ${ }^{*}$ The place on the positive end is held by $Z$. 


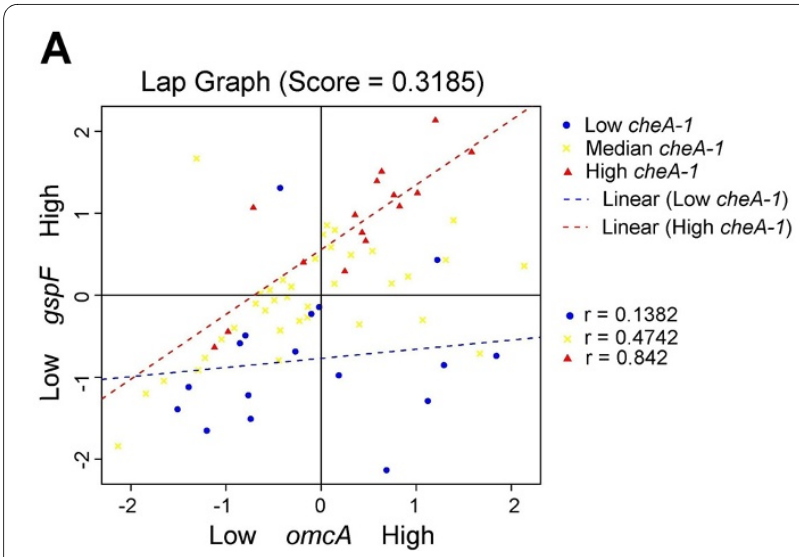

Figure 3 Liquid association pair (LAP) plot for genes (omcA,gspF) as mediated by cheA-1. When cheA-1 is upregulated (red triangles), a positive association is seen. The correlation disappears as the expression of cheA-1 is low (blue dots). The LA score is 0.3185 .

Applying LA system, we are able to find previously unknown relationship between chemotaxis and electron transfer. Thus our study has the potential of helping researchers to break the internal metabolic limitation of the microbes for the MFC efficiency improvement. It is also noteworthy that there are several statistical methods that may extend the LA system for more complex interaction analysis $[26,46-48]$.

\section{Methods}

We extracted expression profiles of S. oneidensis MR-1 from series GSE3876, GSE4489, and GSE7973 in GEO. GSE3876 contained 20 conditions profiled over a period of $1 \mathrm{~h}$ after the 40 Gy IR exposure [49]. GSE4489 contained 60 conditions profiled after a temperature downshift from $30^{\circ} \mathrm{C}$ to $8^{\circ} \mathrm{C}$ or $15^{\circ} \mathrm{C}$ over a period of $160 \mathrm{~min}$ [50]. GSE7973 consisted of 8 conditions profiled tran-

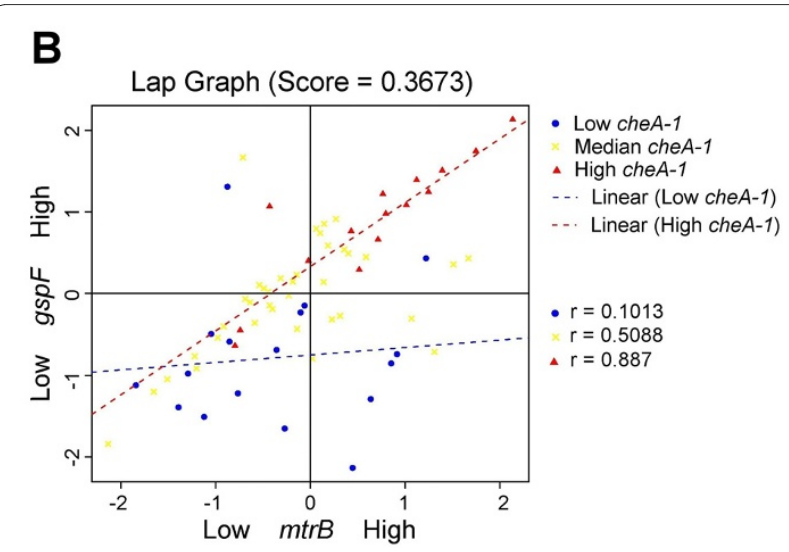

Figure 4 Liquid association pair (LAP) plot for genes (mtrB,gspF) as mediated by cheA-1. When cheA-1 is upregulated (red triangles), a positive association is seen. The correlation disappears as the expression of cheA-1 is low (blue dots). The LA score is 0.3673 .

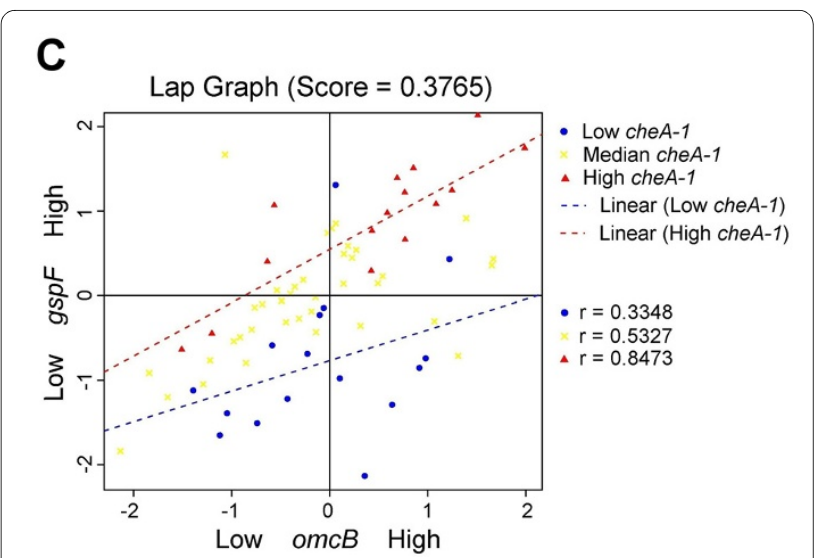

Figure 5 Liquid association pair (LAP) plot for genes (omcB,gspF) as mediated by cheA-1. When cheA-1 is upregulated (red triangles), a positive association is seen. The correlation disappears as the expression of cheA-1 is low (blue dots). The LA score is 0.3765 .

scriptomic differences between $\operatorname{arc} A$ (about aerobic respiration control) knockout mutant and wild-type under aerobic or anaerobic environments [51].

\section{Liquid association analysis}

One basic mode of applying LA method is to set $X=$ name of gene $\mathrm{A}, \mathrm{Y}=$ name of gene $\mathrm{B}, \mathrm{Z}=$ any gene. The computer will search the database and find a small set of genes $\mathrm{Z}$ that are most influential in mediating the correlation pattern between genes $A$ and $B$. If an increase in $Z$ is associated with an increase in the correlation of $(\mathrm{X}, \mathrm{Y})$, then gene $\mathrm{Z}$ is a positive LA-scouting gene for $(\mathrm{X}, \mathrm{Y})$, and a positive liquid association score $L A(X, Y \mid Z)$ is assigned to quantify the strength of LA. The pair $(X, Y)$ is called a positive LA pair (LAP) of Z. Similarly, a negative LAscouting gene can be defined if an increase in $\mathrm{Z}$ is associated with a decrease in the correlation of $(\mathrm{X}, \mathrm{Y})$, and the

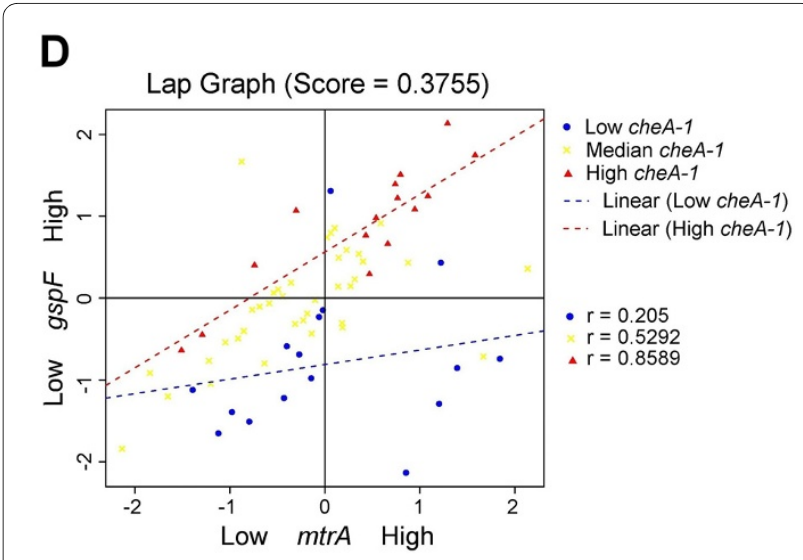

Figure 6 Liquid association pair (LAP) plot for genes ( $m t r A, g s p F)$ as mediated by cheA-1. When cheA-1 is upregulated (red triangles), a positive association is seen. The correlation disappears as the expression of cheA-1 is low (blue dots). The LA score is 0.3755 . 
LA score $L A(X, Y \mid Z)$ is negative. Consequently, when comparing the low with the high expression levels of a negative LA-scouting gene, the scouted LAP is likely to change from being coexpressed to being contraexpressed. For a positive LA-scouting gene, the change goes in the opposite direction: from contraexpression to coexpression [22].

Because the conditions in our dataset come from three different experiments (IR exposure, cold shock, and $\operatorname{arcA}$ deletion mutant), a normal score transformation on each gene profile for each GEO series was performed individually first. After transformation, we use the formulae, $L A(X, Y \mid Z)=\left(\mathrm{X}_{1} \mathrm{Y}_{1} \mathrm{Z}_{1}+\ldots+\mathrm{X}_{88} \mathrm{Y}_{88} \mathrm{Z}_{88}\right) / 88$, to compute the LA score [22,28]. The LAP3 website [52] was developed to enhance the online computation of LA. This website also creates LA graphs, performs standard correlation analysis, reports $P$ value, and provides gene ontology (GO) terms [53] of resulting genes of both positive LAscouting genes (TOP list of $\mathrm{Z}$ ) and negative LA-scouting genes (BOT list of $\mathrm{Z}$ ). All annotations in this study were extracted from NCBI or GO database.

\section{Additional material}

Additional file 1 Liquid association of 21 LAPs related electron transfer pathways. This file contains a table listing liquid association of 21 LAPs related electron transfer pathways.

Additional file 2 ARP gene-crp-initiated liquid association search identifies cheA-1 and $\boldsymbol{m g t E - 1}$. This file contains a table showing cheA-1 and $m g t E-1$ are among the leading 20 positive LA-scouting genes when taking $m t r B$, omcB, $m$ tr $A$ and $c r p$ as the lead.

Additional file 3 ARP gene-chemoreceptor gene-initiated liquid association search identifies cheA-1. This file contains a table showing cheA-1 is among the leading 20 positive LA-scouting genes when taking $g s p F$, omcB, mtrA, $m$ trB, omcA, gspD, SO3282, SO4454 and SO2240 as the lead.

Additional file 4 Liquid association search identifies cheA-1 and mgtE-1. This file contains a table showing cheA-1 and $m g t E-1$ would be identified when taking gspF, $m$ trA, omcB, gspD, omcA, petC and $S O 1415$ as the lead. petC (SO0610) and SO1415 are not clustered with the genes (SO1776-9 and SO0166-8) in the genome.

\section{Abbreviations}

ARP: anaerobic respiratory plasticity; OM: outer membrane; MFCs: microbial fuel cells; T2S: type II secretion system; CDSs: protein-encoding open reading frames; LA: liquid association; che: chemotaxis; IR: ionizing radiation; LAP: LA pair; GO: gene ontology.

\section{Authors' contributions}

SKT, GW, SY, and KCL conducted LA analysis. SKT and KCL wrote the paper. All authors read and approved the final manuscript.

\section{Acknowledgements}

The research was supported in part by NSC grants 95-3114-P-002-005-Y and 97-2627-P-001-003 from the National Science Council, Taiwan. Li's research was also supported by National Science Foundation Grant DMS-0707160. We thank Prof. Jizhong Zhou of University of Oklahoma and Prof. Haichun Gao of Zhejiang University for discussing GEO microarray data; Prof. Mandy J. Ward of University of Southern California for the helpful personal communication; Mr. Chao-Teng Wu, Mr. Cheng-Tao Chen, and others at MIB, ISS, AS. We also thank three anonymous reviewers who provided valuable suggestions for improving the manuscript.

\section{Author Details}

IInstitute of Statistical Science, Academia Sinica, Taipei 115, Taiwan and 2Department of Statistics, University of California, Los Angeles, CA 90095-1554, USA

Received: 19 October 2009 Accepted: 21 May 2010

Published: 21 May 2010

\section{References}

1. Myers $\mathrm{CR}$, Nealson $\mathrm{KH}$ : Bacterial manganese reduction and growth with manganese oxide as the sole electron acceptor. Science 1988, 240:1319-1321

2. Leys D, Tsapin AS, Nealson KH, Meyer TE, Cusanovich MA, Van Beeumen JJ: Structure and mechanism of the flavocytochrome $c$ fumarate reductase of Shewanella putrefaciens MR-1. Nat Struct Biol 1999, 6:1113-1117.

3. Venkateswaran K, Moser DP, Dollhopf ME, Lies DP, Saffarini DA, MacGregor BJ, Ringelberg DB, White DC, Nishijima M, Sano H, Burghardt J, Stackebrandt E, Nealson KH: Polyphasic taxonomy of the genus Shewanella and description of Shewanella oneidensis sp. nov. Int J Syst Bacteriol 1999, 49:705-724

4. Tang YJ, Meadows AL, Kirby J, Keasling JD: Anaerobic central metabolic pathways in Shewanella oneidensis MR-1 reinterpreted in the light of isotopic metabolite labeling. J Bacterio/ 2007, 189:894-901.

5. Nealson KH, Saffarini D: Iron and manganese in anaerobic respiration: environmental significance, physiology, and regulation. Annu Rev Microbiol 1994, 48:311-343.

6. Abdelouas A, Lu Y, Lutze W, Nuttall EH: Reduction of U(VI) to U(IV) by indigenous bacteria in contaminated ground water. $J$ Contam Hydrol 1998, 35:217-233.

7. Heidelberg JF, Paulsen IT, Nelson KE, Gaidos EJ, Nelson WC, Read TD, Eisen JA, Seshadri R, Ward N, Methe B, Clayton RA, Meyer T, Tsapin A, Scott J, Beanan M, Brinkac L, Daugherty S, DeBoy RT, Dodson RJ, Durkin AS, Haft DH, Kolonay JF, Madupu R, Peterson JD, Umayam LA, White O, Wolf AM, Vamathevan J, Weidman J, Impraim M, et al:: Genome sequence of the dissimilatory metal ion-reducing bacterium Shewanella oneidensis. Nat Biotechnol 2002, 20:1118-1123.

8. Brown SD, Thompson MR, Verberkmoes NC, Chourey K, Shah M, Zhou J, Hettich RL, Thompson DK: Molecular dynamics of the Shewanella oneidensis response to chromate stress. Mol Cell Proteomics 2006, 5:1054-1071.

9. Boukhalfa H, Icopini GA, Reilly SD, Neu MP: Plutonium(IV) reduction by the metal-reducing bacteria Geobacter metallireducens GS15 and Shewanella oneidensis MR1. Appl Environ Microbiol 2007, 73:5897-5903.

10. Liu C, Jeon BH, Zachara JM, Wang Z: Influence of calcium on microbial reduction of solid phase uranium(VI). Biotechnol Bioeng 2007, 97:1415-1422

11. Ross DE, Ruebush SS, Brantley SL, Hartshorne RS, Clarke TA, Richardson DJ, Tien M: Characterization of protein-protein interactions involved in iron reduction by Shewanella oneidensis MR-1. Appl Environ Microbiol 2007, 73:5797-5808

12. Shi L, Squier TC, Zachara JM, Fredrickson JK: Respiration of metal (hydr)oxides by Shewanella and Geobacter: a key role for multihaem ctype cytochromes. Mol Microbiol 2007, 65:12-20.

13. Bretschger O, Obraztsova A, Sturm CA, Chang IS, Gorby YA, Reed SB, Culley DE, Reardon CL, Barua S, Romine MF, Zhou J, Beliaev AS, Bouhenn R, Saffarini D, Mansfeld F, Kim BH, Fredrickson JK, Nealson KH: Current production and metal oxide reduction by Shewanella oneidensis MR-1 wild type and mutants. Appl Environ Microbiol 2007, 73:7003-7012.

14. Myers CR, Myers JM: MtrB is required for proper incorporation of the cytochromes OmcA and OmcB into the outer membrane of Shewanella putrefaciens MR-1. Appl Environ Microbiol 2002, 68:5585-5594

15. Shi L, Chen B, Wang Z, Elias DA, Mayer MU, Gorby YA, Ni S, Lower BH, Kennedy DW, Wunschel DS, Mottaz HM, Marshall MJ, Hill EA, Beliaev AS, Zachara JM, Fredrickson JK, Squier TC: Isolation of a high-affinity functional protein complex between OmcA and MtrC: two outer membrane decaheme $c$-type cytochromes of Shewanella oneidensis MR-1. J Bacterio/ 2006, 188:4705-4714

16. Myers CR, Myers JM: The outer membrane cytochromes of Shewanella oneidensis MR-1 are lipoproteins. Lett App/ Microbio/ 2004, 39:466-470.

17. Gorby YA, Yanina S, McLean JS, Rosso KM, Moyles D, Dohnalkova A, Beveridge TJ, Chang IS, Kim BH, Kim KS, Culley DE, Reed SB, Romine MF, 
Saffarini DA, Hill EA, Shi L, Elias DA, Kennedy DW, Pinchuk G, Watanabe K Ishii S, Logan B, Nealson KH, Fredrickson JK: Electrically conductive bacterial nanowires produced by Shewanella oneidensis strain MR-1 and other microorganisms. Proc Natl Acad Sci USA 2006, 103:11358-11363.

18. Py B, Loiseau L, Barras F: An inner membrane platform in the type II secretion machinery of Gram-negative bacteria. EMBO Rep 2001, 2:244-248.

19. Stern S, Dror T, Stolovicki E, Brenner N, Braun E: Genome-wide transcriptional plasticity underlies cellular adaptation to novel challenge. Mol Syst Biol 2007, 3:106.

20. Karlebach G, Shamir R: Modelling and analysis of gene regulatory networks. Nature Rev Mol Cell Biol 2008, 9:770-780.

21. Spellman PT, Sherlock G, Zhang MQ, Iyer VR, Anders K, Eisen MB, Brown $\mathrm{PO}$, Botstein D, Futcher B: Comprehensive identification of cell cycleregulated genes of the yeast Saccharomyces cerevisiae by microarray hybridization. Mol Biol Cell 1998, 9:3273-3297.

22. Li KC: Genome-wide coexpression dynamics: theory and application. Proc Natl Acad Sci USA 2002, 99:16875-16880.

23. Lin LH, Lee HC, Li WH, Chen BS: A systematic approach to detecting transcription factors in response to environmental stresses. $B M C$ Bioinformatics 2007, 8:473.

24. Pham H, Ferrari R, Cokus SJ, Kurdistani SK, Pellegrini M: Modeling the regulatory network of histone acetylation in Saccharomyces cerevisiae. Mol Syst Biol 2007, 3:153.

25. GEO: Gene Expression Omnibus [http://www.ncbi.nlm.nih.gov/geo/]

26. Li KC, Liu CT, Sun W, Yuan S, Yu T: A system for enhancing genome-wide coexpression dynamics study. Proc Natl Acad Sci USA 2004, 101:15561-15566.

27. Li KC, Yuan S: A functional genomic study on NCl's anticancer drug screen. Pharmacogenomics J 2004 4:127-135.

28. Li KC, Palotie A, Yuan S, Bronnikov D, Chen D, Wei X, Choi OW, Saarela J, Peltonen $\mathrm{L}$ : Finding disease candidate genes by liquid association. Genome Biol 2007, 8:R205.

29. LiU CT, Yuan S, Li KC: Patterns of co-expression for protein complexes by size in Saccharomyces cerevisiae. Nucleic Acids Res 2009, 37:526-532.

30. McCarter LL: Polar flagellar motility of the Vibrionaceae. Microbiol Mol Biol Rev 2001, 65:445-462

31. Li J, Romine MF, Ward MJ: Identification and analysis of a highly conserved chemotaxis gene cluster in Shewanella species. FEMS Microbiol Lett 2007, 273:180-186.

32. Baker MD, Wolanin PM, Stock JB: Signal transduction in bacteria chemotaxis. Bioessays 2006, 28:9-22.

33. Nealson KH, Moser DP, Saffarini DA: Anaerobic electron acceptor chemotaxis in Shewanella putrefaciens. Appl Environ Microbiol 1995, 61:1551-1554.

34. Bencharit S, Ward MJ: Chemotactic responses to metals and anaerobic electron acceptors in Shewanella oneidensis MR-1.J Bacterio/ 2005, 187:5049-5053.

35. Thompson MR, Thompson DK, Hettich RL: Systematic assessment of the benefits and caveats in mining microbial post-translational modifications from shotgun proteomic data: the response of Shewanella oneidensis to chromate exposure. J Proteome Res 2008 7:648-658.

36. Baraquet C, Théraulaz L, lobbi-Nivol C, Méjean V, Jourlin-Castelli C. Unexpected chemoreceptors mediate energy taxis towards electron acceptors in Shewanella oneidensis. Mol Microbiol 2009, 73:278-290.

37. Hau HH, Gilbert A, Coursolle D, Gralnick JA: Mechanism and consequences of anaerobic respiration of cobalt by Shewanella oneidensis strain MR-1. Appl Environ Microbiol 2008, 74:6880-6886.

38. Pham CA, Jung SJ, Phung NT, Lee J, Chang IS, Kim BH, Yi H, Chun J: A novel electrochemically active and $\mathrm{Fe}$ (III)-reducing bacterium phylogenetically related to Aeromonas hydrophila, isolated from a microbial fuel cell. FEMS Microbiol Lett 2003, 223:129-134.

39. Merino S, Gavín R, Altarriba M, Izquierdo L, Maguire ME, Tomás JM: The MgtE $\mathrm{Mg}^{2+}$ transport protein is involved in Aeromonas hydrophila adherence. FEMS Microbiol Lett 2001, 198:189-195.

40. Burkart M, Toguchi A, Harshey RM: The chemotaxis system, but not chemotaxis, is essential for swarming motility in Escherichia coli. Proc Natl Acad Sci USA 1998, 95:2568-2573.
41. Saffarini DA, Schultz R, Beliaev A: Involvement of cyclic AMP (cAMP) and CAMP receptor protein in anaerobic respiration of Shewanella oneidensis. J Bacterio/ 2003, 185:3668-3671.

42. Yang Y, Harris DP, Luo F, Xiong W, Joachimiak M, Wu L, Dehal P, Jacobsen J, Yang Z, Palumbo AV, Arkin AP, Zhou J: Snapshot of iron response in Shewanella oneidensis by gene network reconstruction. BMC Genomics 2009, 10:131.

43. McLean JS, Pinchuk GE, Geydebrekht OV, Bilskis CL, Zakrajsek BA, Hill EA, Saffarini DA, Romine MF, Gorby YA, Fredrickson JK, Beliaev AS: Oxygendependent autoaggregation in Shewanella oneidensis MR-1. Environ Microbiol 2008, 10:1861-1876.

44. Cruz-García C, Murray AE, Klappenbach JA, Stewart V, Tiedje JM: Respiratory nitrate ammonification by Shewanella oneidensis MR-1. $J$ Bacteriol 2007, 189:656-662.

45. Du Z, Li H, Gu T: A state of the art review on microbial fuel cells: A promising technology for wastewater treatment and bioenergy. Biotechnol Adv 2007, 25:464-482

46. Yuan S, Li KC: Context-dependent clustering for dynamic cellular state modeling of microarray gene expression. Bioinformatics 2007 23:3039-3047.

47. Sun W, Yuan S, Li KC: Trait-trait dynamic interaction: 2D-trait eQTL mapping for genetic variation study. BMC Genomics 2008, 9:242.

48. Ho YY, Cope L, Louis TA, Parmigiani G: Generalized liquid association. In Working paper 183 Johns Hopkins University, Department of Biostatistics; 2009

49. Qiu X: Transcriptome analysis applied to survival of Shewanella oneidensis MR-1 exposed to ionizing radiation. J Bacterio/ 2006, 188:1199-1204

50. Gao H, Yang ZK, Wu L, Thompson DK, Zhou J: Global transcriptome analysis of the cold shock response of Shewanella oneidensis MR-1 and mutational analysis of its classical cold shock proteins. J Bacteriol 2006, 188:4560-4569

51. Gao H, Wang X, Yang ZK, Palzkill T, Zhou J: Probing regulon of ArcA in Shewanella oneidensis MR-1 by integrated genomic analyses. BMC Genomics 2008, 9:42.

52. Liquid Association Website [http://kiefer.stat2.sinica.edu.tw/LAP3/ index.php]

53. Ashburner M, Ball CA, Blake JA, Botstein D, Butler H, Cherry JM, Davis AP, Dolinski K, Dwight SS, Eppig JT, Harris MA, Hill DP, Issel-Tarver L, Kasarskis A, Lewis S, Matese JC, Richardson JE, Ringwald M, Rubin GM, Sherlock G: Gene ontology: tool for the unification of biology. The Gene Ontology Consortium. Nature Genet 2000, 25:25-29.

doi: 10.1186/1471-2164-11-319

Cite this article as: Tai et al., Genome-wide expression links the electron transfer pathway of Shewanella oneidensis to chemotaxis BMC Genomics 2010, 11:319

\section{Submit your next manuscript to BioMed Centra and take full advantage of:}

- Convenient online submission

- Thorough peer review

- No space constraints or color figure charges

- Immediate publication on acceptance

- Inclusion in PubMed, CAS, Scopus and Google Scholar

- Research which is freely available for redistribution
C BioMed Central 